\title{
Biomechanics of the Sacroiliac Joint: Surgical Treatments
}

\author{
AMIN JOUKAR, MS, ${ }^{1}$ ALI KIAPOUR, PHD, ${ }^{1,2}$ HOSSEIN ELGAFY, MD, ${ }^{1}$ DENIZ U. ERBULUT, PHD, ${ }^{1}$ \\ ANAND K. AGARWAL, MD, ${ }^{1}$ VIJAY K. GOEL, PHD ${ }^{1}$ \\ ${ }^{I}$ Engineering Center for Orthopaedic Research Excellence (E-CORE), Departments of Bioengineering and Orthopaedics, The University of Toledo, Toledo, Ohio, \\ ${ }^{2}$ Department of Neurosurgery, Massachusetts General Hospital, Harvard Medical School, Boston, Massachusetts
}

\begin{abstract}
Background: Fixation is one of the most common surgical techniques for the treatment of chronic pain originating from the sacroiliac joint (SIJ). Many studies have investigated the clinical outcomes and biomechanics of various SIJ surgical procedures. However, the biomechanical literature points to several issues that need to be further explored, especially for the devices used in minimally invasive surgery of the SIJ. This study (part II) aims to assess biomechanical literature to understand the existing information as it relates to efficacies of the surgical techniques and the gaps in the knowledge base. Part I reviewed basic anatomy and mechanics of the SIJ joint, including difference between males and females, and causes of pain emanating from these joints.

Methods: A thorough literature review was performed pertaining to studies related to SIJ fixation techniques and the biomechanical outcomes of the surgical procedures.

Results: Fifty-five studies matched the search criteria and were considered for the review. These articles predominantly pertained to the biomechanical outcomes of the minimally invasive surgery with different instrumentation systems and surgical settings.

Conclusions: The SIJ is one of the most overlooked sources of lower back pain. The joint is responsible for the pain in $15 \%$ to $30 \%$ of people suffering from lower back pain. Various studies have investigated the clinical outcomes of different surgical procedures intended to improve the pain and quality of life following surgery. The data show that these techniques are indeed effective. However, clinical studies have raised several issues, like optimal number and positioning of implants, unilateral versus bilateral placements, adjacent segment disease, implant designs, and optimal location of implants with respect to variations in bone density across the SIJ. Biomechanical studies using in vitro and in silico techniques have addressed some of these issues. Studies also point out the need for additional investigations for a better understanding of the underlying mechanics for the improved long-term surgical outcomes. Further long-term clinical follow-ups are essential as well. This review presents pertinent findings.
\end{abstract}

Biomechanics

Keywords: biomechanics, sacroiliac joint, low back pain, sacroiliac fixation, minimally invasive, surgical procedures, devices

\section{BACKGROUND}

Low back pain (LBP) is the most common reason for primary care visits after the common cold, with approximately $90 \%$ of adults being affected by this condition at some point in their lives. ${ }^{1,2}$ Apart from hindering the quality of life of those affected by LBP, if left untreated or improperly diagnosed, patients' work productivity, and subsequently the economy, may be adversely affected. LBP accounts for an annual cost up to 60 billion dollars due to decreased productivity and income, and increased medical expenses. ${ }^{3-5}$

The majority of LBP originates from the lumbar spine. However, one of the most overlooked sources of LBP is the sacroiliac joint (SIJ) due to its complex nature. ${ }^{2}$ Recent studies have reported a higher prevalence of the SIJ as a source for LBP, with some reports having estimated that the SIJ is the actual source of pain in $15 \%$ to $30 \%$ of cases. ${ }^{6-8}$ Increased physicians' awareness of the prevalence of the SIJ as a source of LBP has given rise to an increased clinical suspicion of joint dysfunction as a pain generator. Hence, appropriate planning of treatment strategies is becoming a norm.

Current nonsurgical treatment and pain management strategies include physical therapy, SIJ injections, and radiofrequency ablation. When patients continue to present chronic LBP characteristic of SIJ dysfunction, surgical procedures become the final resort. This review article addresses the diagnosis of SIJ dysfunction, treatments, surgical techniques, and biomechanics of the SIJ. It builds 
on the part I review that delineates the basic anatomy, differences between females and males, role of ligaments in providing stability, load sharing among various structures, and the numerous causes of LBP emanating from the SIJ.

\section{DIAGNOSIS OF SIJ DYSFUNCTION}

Symptoms of SIJ dysfunction include pain in the lower back, buttock, back of the thigh, and knee. Patients with LBP often experience pain during sitting and leaning forward, with an increase in intra-abdominal pressure. ${ }^{9}$ While these pain characteristics are associated with SIJ dysfunction, they are also consistent with other hip and spine conditions, making accurate diagnosis and confirmation of the SIJ as the pain source a rather difficult task.

Due to the complexity of diagnosing the SIJ as the pain source, numerous physical tests are in use, many of which incorporate distraction of the SIJs. Two of the most commonly performed tests are the Gaenslen test and Patrick test, also known as the FABER test. ${ }^{10}$ Other provocation tests for assessing SIJ pain include distraction/compression tests, the thigh thrust test, and the sacral thrust test. ${ }^{11}$ If 3 or more of these tests are positive, then diagnosing the SIJ as the source of pain is acceptable. ${ }^{12}$ However, many clinical studies have shown rather inconsistent findings in the success of identifying the pain source to be SIJ dysfunction., ${ }^{8,10}$ Thus to improve reliability, further examinations are achieved through other techniques (eg, radiological studies and diagnostic blocks, or intra-articular injections). Radiological imaging with diagnostic injections, however, have yielded low sensitivities and poor correlations with symptoms. ${ }^{10}$ An exception is the high specificity of magnetic resonance imaging in the setting of the seronegative spondylo-arthropathies (90\%-100\%). ${ }^{13-15}$ Diagnostic blocks, on the other hand, are the most reliable methods for diagnosing SIJ pain. These blocks, administered under fluoroscopy, are used to determine if a patient experiences a significant reduction in pain while the anesthetic is active. $^{16}$

\section{TREATMENT OF SIJ DYSFUNCTION- SURGICAL TECHNIQUES AND NEED FOR IN VITRO AND IN SILICO STUDIES}

Several options exist for treatment of SIJ dysfunction and associated pain, ranging from conservative to minimally invasive and open surgeries. Nonsurgical management options include physical therapy, steroid injections, radiofrequency ablation, and prolotherapy; these are recommended for the early stages of SIJ dysfunction. Under specific conditions such as patients with leg length discrepancy, only using shoe inserts can help eliminating the discrepancy, consequentially equalizing and decreasing the load distribution across the joints over time. ${ }^{10,17}$ However, when the nonsurgical treatment plans fail to overcome the pain and improve the patient's conditions, surgery (open or minimally invasive) is a viable option.

\section{Open SIJ Fusion}

When nonsurgical management strategies fail to reduce patient pain and discomfort due to SIJ dysfunction, surgical measures become an option, beginning with open arthrodesis, or fusion of the SIJ. According to Smith et al, ${ }^{18}$ open surgical fusion surgery requires longer operative time and hospital stay and caused greater blood loss. Apart from having less advantageous operative measures, open arthrodesis of the SIJ also showed less superior SIJ pain rating changes over the 12- and 24-month follow-ups, compared with minimally invasive surgical approaches for fusion, described next.

\section{Minimally Invasive SIJ Fusion}

Minimal invasive surgeries of the SIJ have become quite common these days. Thus, it is advantageous to understand the general procedure for the design and execution of biomechanical studies. During a minimally invasive SIJ fusion procedure, the patient is administered general anesthesia and lies in the prone position for intraoperative fluoroscopy. ${ }^{4,79}$ In general, a long lateral incision of the buttocks is the first step to provide access to the joint. Then the gluteal fascia is penetrated and dissected to reach the outer table of the ilium. A Steinmann pin is passed through the ilium across the SI joint to the middle of the sacrum and lateral to the neural foramen. ${ }^{20}$ The pin enables a soft tissue protector to slide over it for the bone decortication. Upon removal of the drill, a broach is malleted across the joint to prepare a channel for the first implant and using a pin guidance system allows implant placement. Finally, the incision is irrigated and tissue layers are closed. ${ }^{4,7,18,20,21} \mathrm{~A}$ large number of fusion implant designs are available on the market. Clinical follow-ups assist in evaluating the efficacy of these implants. These clinical follow-ups also highlight some of the mechanical 

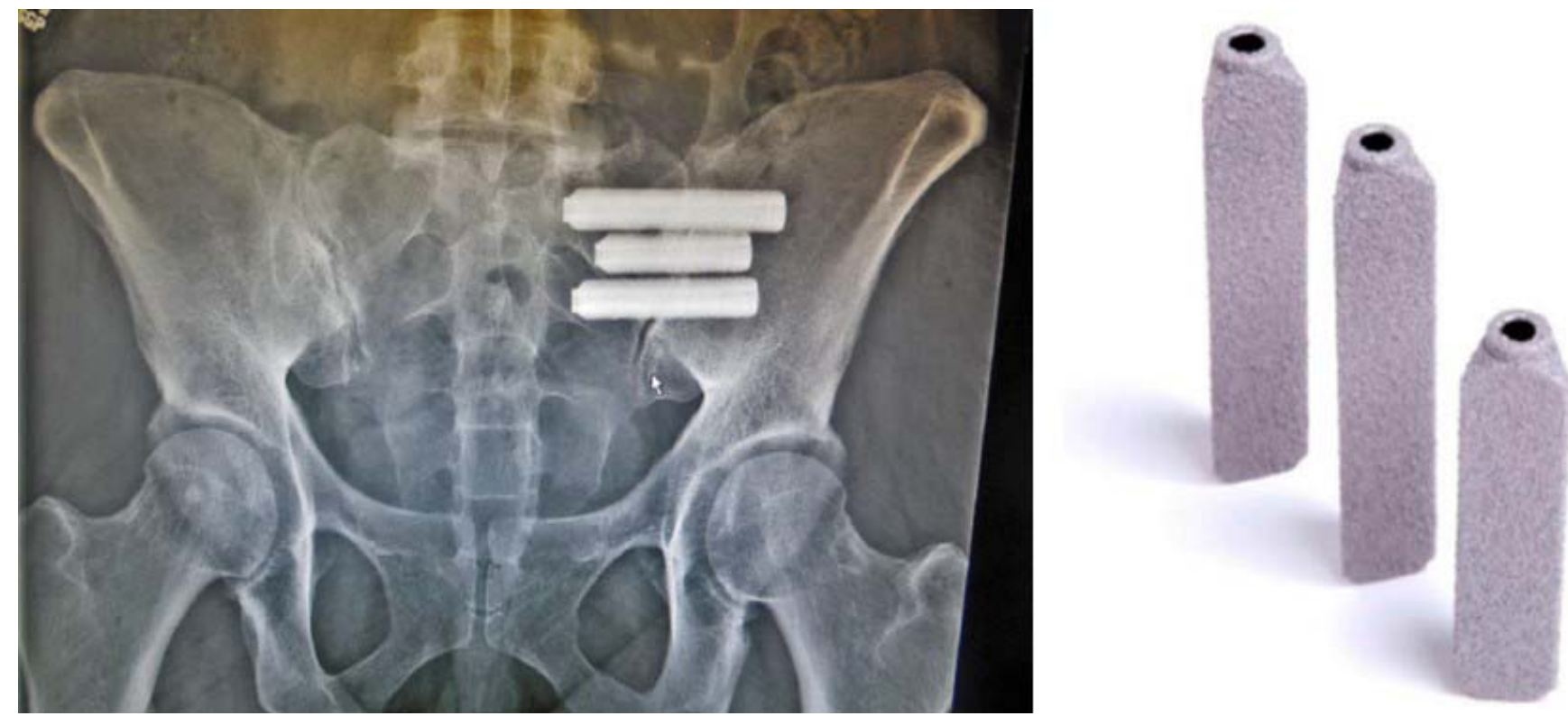

Figure 1. Triangular titanium implant with porous coating; lateral approach. ${ }^{25}$

issues that need further exploring using in vitro and in silico studies.

Among the different devices for minimally invasive SIJ fusion, perhaps the iFuse implant system (SI-Bone, Inc, Santa Clara, CA) is the most used at present; this system consists of porous titanium plasma spray-coated triangular titanium implants. The shape, coating, and interference fit of these implants allow for initial stabilization or mechanical fixation, and biological fixation leads to effective stabilization of the joint over time., ${ }^{4,18,22}$ The device's several unique features differentiate it from traditional cages and screws. In these implants, interference fit allows proper fixation, the triangular profile reduces implant rotation, and the porous surface minimizes the implant micromotion and enhances bone ingrowth resulting in better fusion. Biomechanical studies showed that an 8-mm cannulated screw is 3 times weaker in shear and bending than a triangular implant (Figure 1). ${ }^{23}$ In this system, no grafts are placed in the SIJ; therefore, all fusions are obtained through the bony ingrowth across the porous coating. ${ }^{24}$

The SI-LOK SIJ fixation system (Globus Medical, Inc, Audubon, PA) is another minimally invasive surgical SIJ fixation device that places 3 hydroxyapatite-coated screws laterally across the sacroiliac joints (Figure 2). There is an optional bone graft slot inside the screw to enhance fusion. An optional lag screw thread allows compression force during placement. $^{26}$
The SImmetry SIJ fusion system, produced by Zyga Technology, Inc (Minnetonka, MN), is a cannulated titanium implant used with 2 screws (one is an antirotation screw) placed laterally across the SIJ (Figure 3). The cannulated threaded implant and the antirotation screw have diameters of 12.5 $\mathrm{mm}$ and $6.5 \mathrm{~mm}$, respectively. There is no bone graft slot in this system, and the bone graft is placed across the articular part of the joint. ${ }^{27}$

SIFix, developed by NuTech Medical, Inc (Birmingham, AL), is one of the posterior minimally invasive surgical SIJ fixation systems that uses 2 threaded cancellous bone dowels to stabilize the joint. The concept minimizes damage to the ligaments and provides compression to promote fusion/union across the SIJ. Bilateral placements with a single midline incision are also feasible with this design (Figure 4).

The RI-ALTO implant, made by Medtronic, Inc (Minneapolis, MN), is another posterior minimally invasive surgical SIJ fusion system; it uses 2 or 3 threaded screws to stabilize the joint. The procedure is safe and effective in SIJ fusion and reduces surgical morbidity due to its posterior approach (Figure 5).

In conclusion, significantly successful reports of surgical outcomes, patient satisfaction, recovery rate, and implant survivorship, show that minimally invasive procedures have the potential to become the predominant focus for treating patients with chronic SIJ pain. Furthermore, there are various 

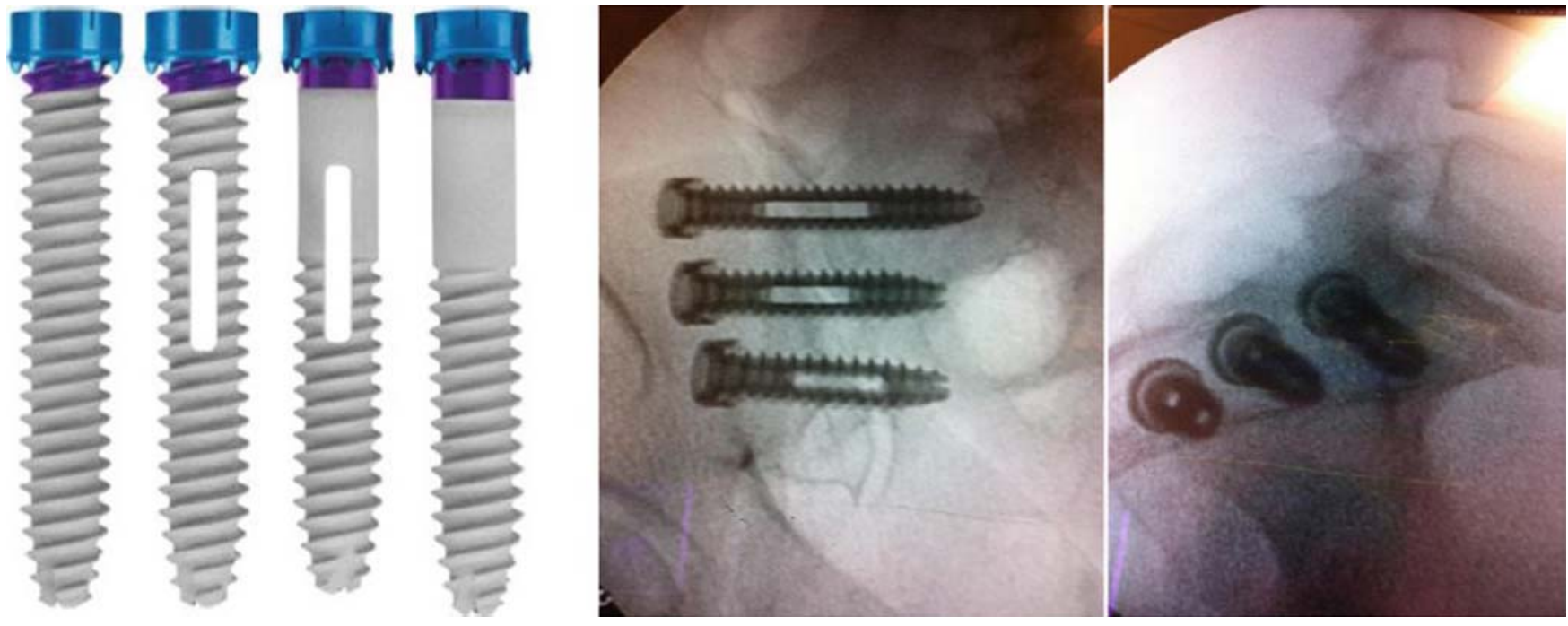

Figure 2. SI-LOK sacroiliac joint fixation system; lateral approach. ${ }^{26}$

techniques and different types or designs of SIJ fusion implants. These studies, however, do not elucidate the biomechanical effects of surgical parameters such as number and positioning of implants one may use, unilateral versus bilateral placement, etc.

Another issue is the relationship between sacral bone density and surgical outcomes of the fusion procedures. A review of literature on clinical outcomes of SIJ fixation techniques shows that loosening of the hardware at the sacral side seems to be most common. The implant loosening or failure often occurs due to poor bone quality in the sacrum area. ${ }^{30}$ Several studies have investigated the relationship between sacral bone density and lumbosacral fusion rate. These studies have shown up to $45 \%$ of sacro-pelvic fixations fail due to S1 screw
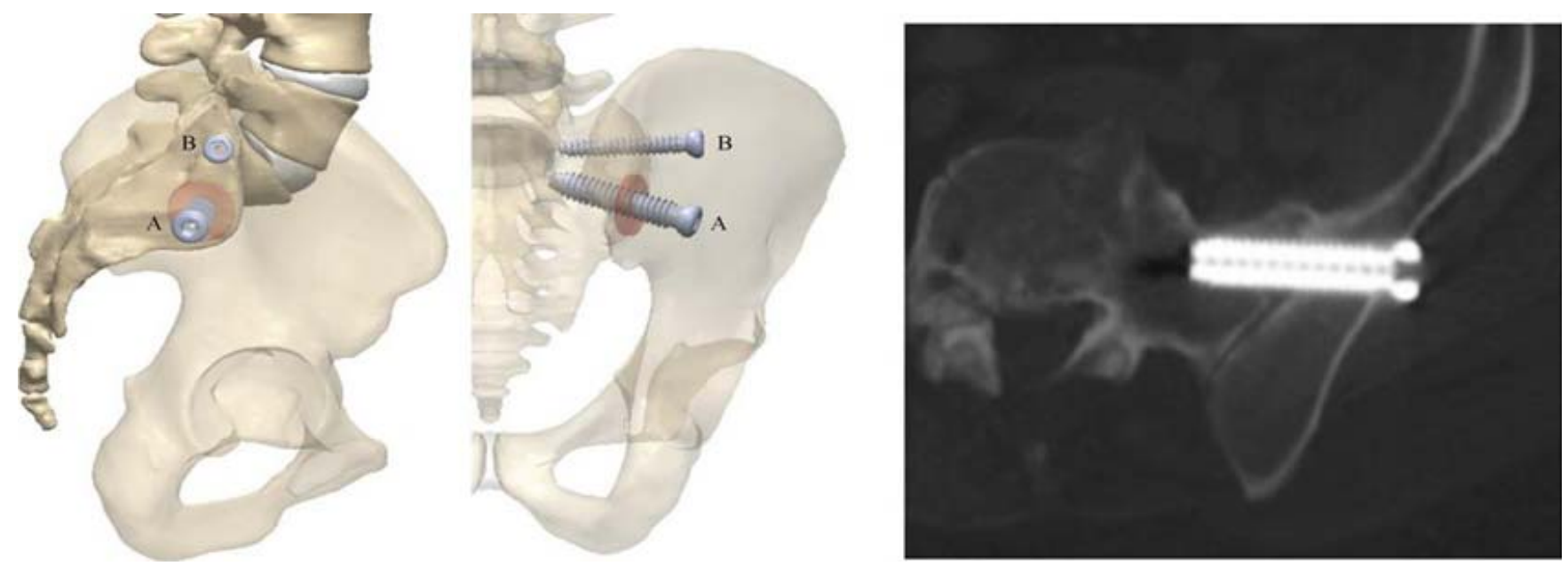

haloing or pullout. Other studies reported inferior screw pullout strength of the sacral screws in sacral bone with low mineral density. ${ }^{30-32}$

Several clinical studies have reported serious complications following surgical treatment of unstable posterior pelvic ring injuries using SIJ fixation methods. ${ }^{33,34}$ The reported complications included loss of fixation, loss of function, neurovascular injury, and mal-union.

Placement of ilio-sacral screws into the S1 body has been recommended as the preferred method of fixation by these studies; although sacral dysmorphism and size limitation may prevent fixation of S1 using this method. ${ }^{34,35}$ In such cases, alternative methods become essential, like fixation into the second sacral body (S2). ${ }^{36,37}$ However, the smaller size of the second sacral body results in a decreased

Figure 3. SImmetry sacroiliac joint fusion system; lateral approach. ${ }^{27}$ 


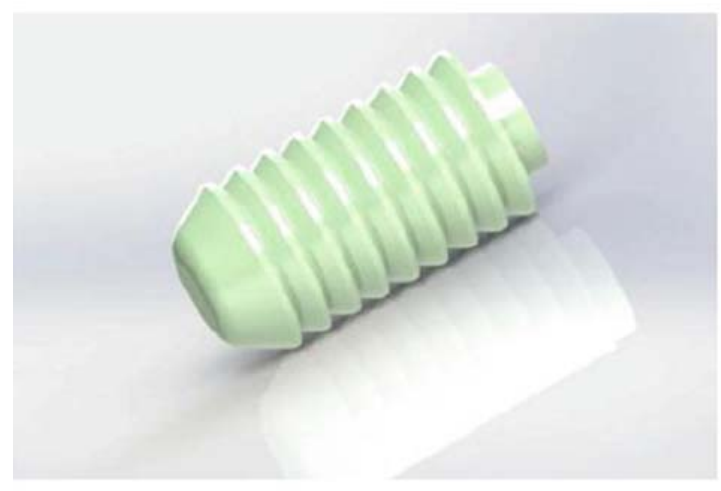

Figure 4. SIFix sacroiliac joint fixation system; posterior approach. ${ }^{28}$

tolerance of variant screw trajectories. Thus, achieving a proper fixation into this segment remains the main challenge. ${ }^{37,38}$ The effect of the quality of the surrounding bone in the S2 body on the surgical outcomes are lacking in the literature.

Thus, biomechanical studies using in vitro and in silico techniques are crucial in addressing the above stated questions.

\section{In Vitro Studies}

Soriano-Baron et $\mathrm{al}^{39}$ investigated the effects of placement of triangular implants across the SIJ on range of motion (ROM) versus load for a one-leg standing posture. Nine fresh frozen specimens were sequentially tested; the intact pubic symphysis was cut to allow the right and left SIJs to move freely following stabilization. Implants were located through the posterior and transarticular approaches. In the posterior procedure, the 3 implants were inline in the inlet view, and parallel in the outlet and lateral views. In the transarticular approach, the locations of superior and inferior implants were

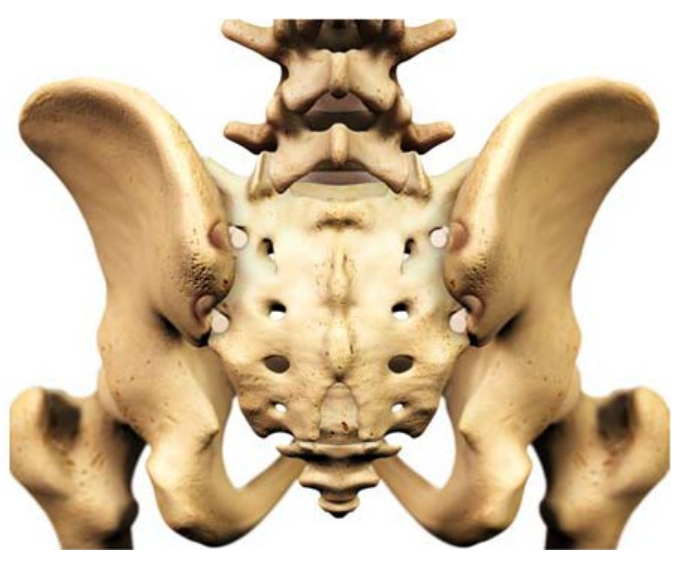

similar to the posterior technique, and the middle implant was located towards the anterior third of the sacrum across the cartilaginous portion of the SIJ. Pure moments up to $7.5 \mathrm{Nm}$ simulated flexion, extension, lateral bending, and axial rotations under the one-leg stance. Placement of 3 implants in both approaches significantly reduced the ROM in all modes. However, there was no significant difference between these 2 techniques regarding motion reduction. ${ }^{39}$ The authors extended ${ }^{22}$ the investigation to study the effects of 5000 cyclic loads on the stabilization characteristics of the fused specimens. The ROM following cyclic loading did not change much, compared precyclic test data.

Lindsey et $\mathrm{al}^{25}$ compared the stabilization characteristics of unilateral and bilateral triangular implant placements across the SIJ during the oneleg stance condition. Unilateral instrumentation significantly decreased the ROM of the treated side, and did not affect nontreated contralateral SIJ motion during the one-leg stance condition. Bilateral placements reduced motions on both sides.
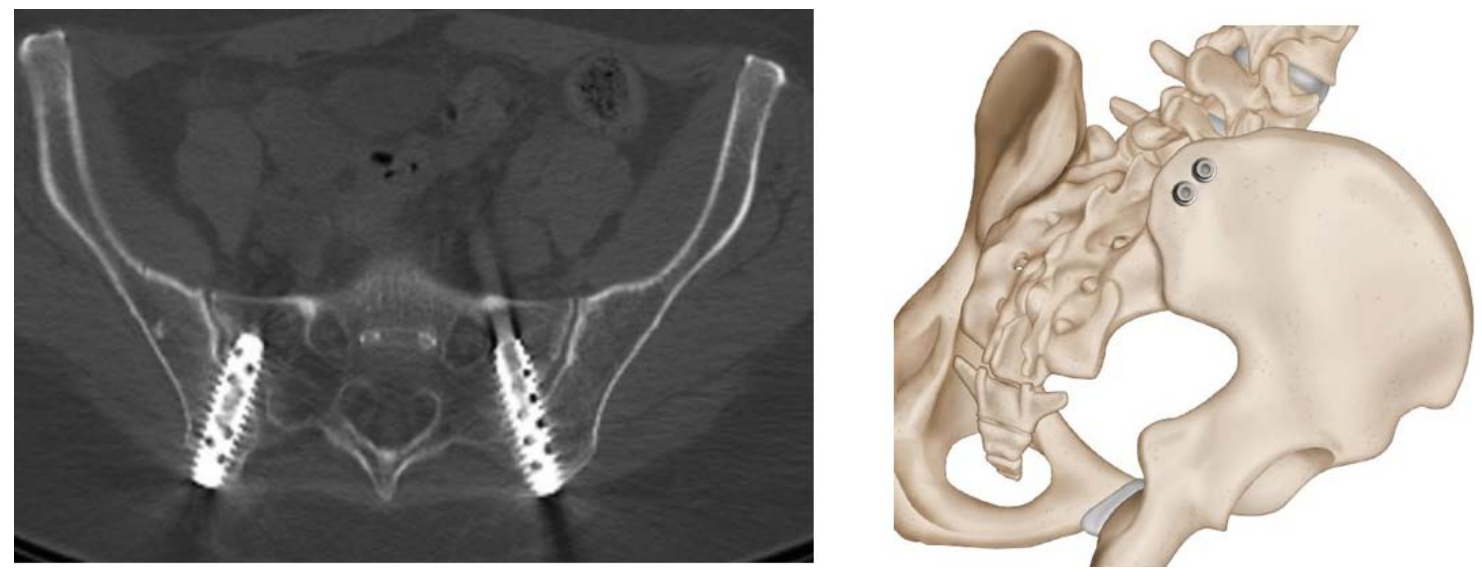

Figure 5. RI-ALTO sacroiliac joint fusion system; posterior approach. ${ }^{29}$ 

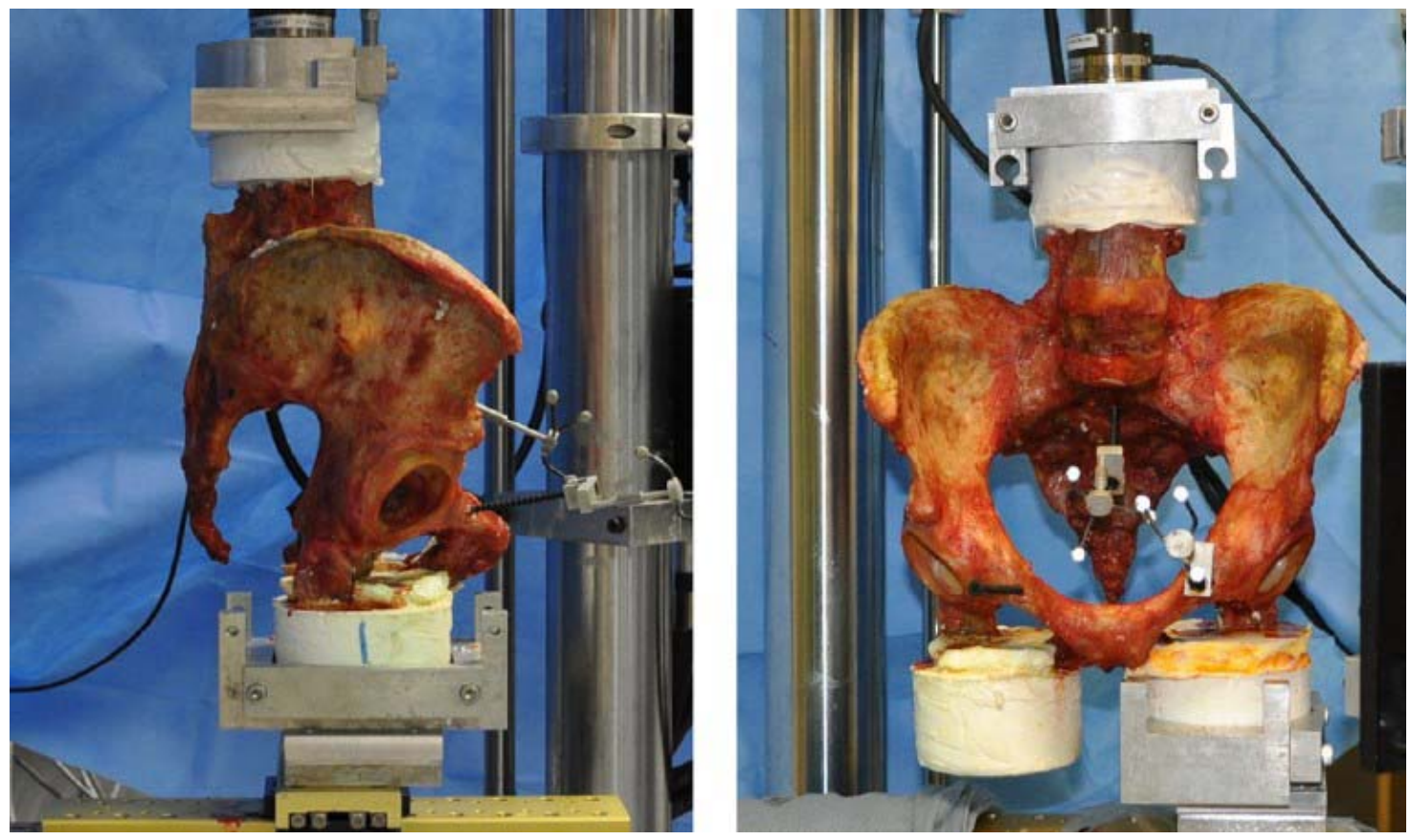

Figure 6. Test setup side view (left) and anterior view (right) under bending moment in materials testing system machine. ${ }^{41}$

Thus, bilateral instrumentation becomes essential if one wants to reduce the ROM of both of the SIJs.

Jeong et $\mathrm{al}^{40}$ assessed the mobility in 3 groups of intact, unilateral, and bilateral fusions using 3 triangular implants in each joint. The loading was pure bending moment of $7.5 \mathrm{Nm}$ under single-leg stance. They observed that unilateral and bilateral SIJ fusions using iFuse implants provided significant reduction in SIJ motions, compared to being intact in all modes. ${ }^{40}$

Shih et $\mathrm{al}^{41}$ performed an in vitro study to evaluate 2 techniques for placing primary $(12.5-\mathrm{mm})$ and secondary $(8.5-\mathrm{mm})$ threaded rods (Zyga Technology) across the SIJ (Figure 6). They performed cyclic loading after placement of the primary implant at $\mathrm{S} 1$ and a secondary implant at either S1 or S2. The fixation using 2 threaded rods significantly reduced SIJ motion and the location of the secondary $8.5-\mathrm{mm}$ implant did not alter construct performance.

Doud $^{42}$ investigated the biomechanics of SIFix fusion technique in a cadaver model. They applied a cyclic compression force ranging from 0.2 to 2.5 times the specimen's body weight for a double-leg stance and 0.6 to 1.8 times the body weight for a single-leg stance to mimic walking. The treated SIJ with SIFix did not provide any reduction in motion following fixation, compared with intact cases.

Recently, a biomechanical study on the SIIntegrity SIJ fusion system was done. ${ }^{43}$ This implant was similar to SImmetry SIJ fusion. It uses 1 lag screw along with another smaller anti-rotation screw. L4-pelvis specimens were tested intact, destabilized, and instrumented groups in single-leg stance under $7.5 \mathrm{Nm}$ pure moments. The posterior SIJ capsule and ligaments and the pubic symphysis were dissected to destabilize the specimen. They showed that instrumentation significantly reduced the ROM of the joint, compared with the destabilized condition but had similar ROM in flexion/ extension and axial rotation, compared with the intact condition.

Lumbar spine fusion, particularly of the L5-S1 segment, affects the biomechanics of the SIJ by increasing both the motion and stresses across its articular surface. ${ }^{9}$ Bariah $^{44}$ determined spinal motions for double- and single-leg stance cases in 4 configurations of intact, L4-L5 fusion, L4-S1 fusion, and unilateral SIJ fixation, using a single 9-mm screw (Figure 7). The effects of body weight and spinal motions were simulated by applying moments (7.5 Nm for torsion and $8.5 \mathrm{Nm}$ for flexion/ extension), in addition to preloads. They showed that spinal and lumbosacral fusions led to an increase in SIJ ROM. The SIJs during axial compression, exhibited an increase in anterior motion for the stabilized case as well. The motion at the posterior SIJs increased during all modes of motions (flexion/extension, torsion and axial compression). 


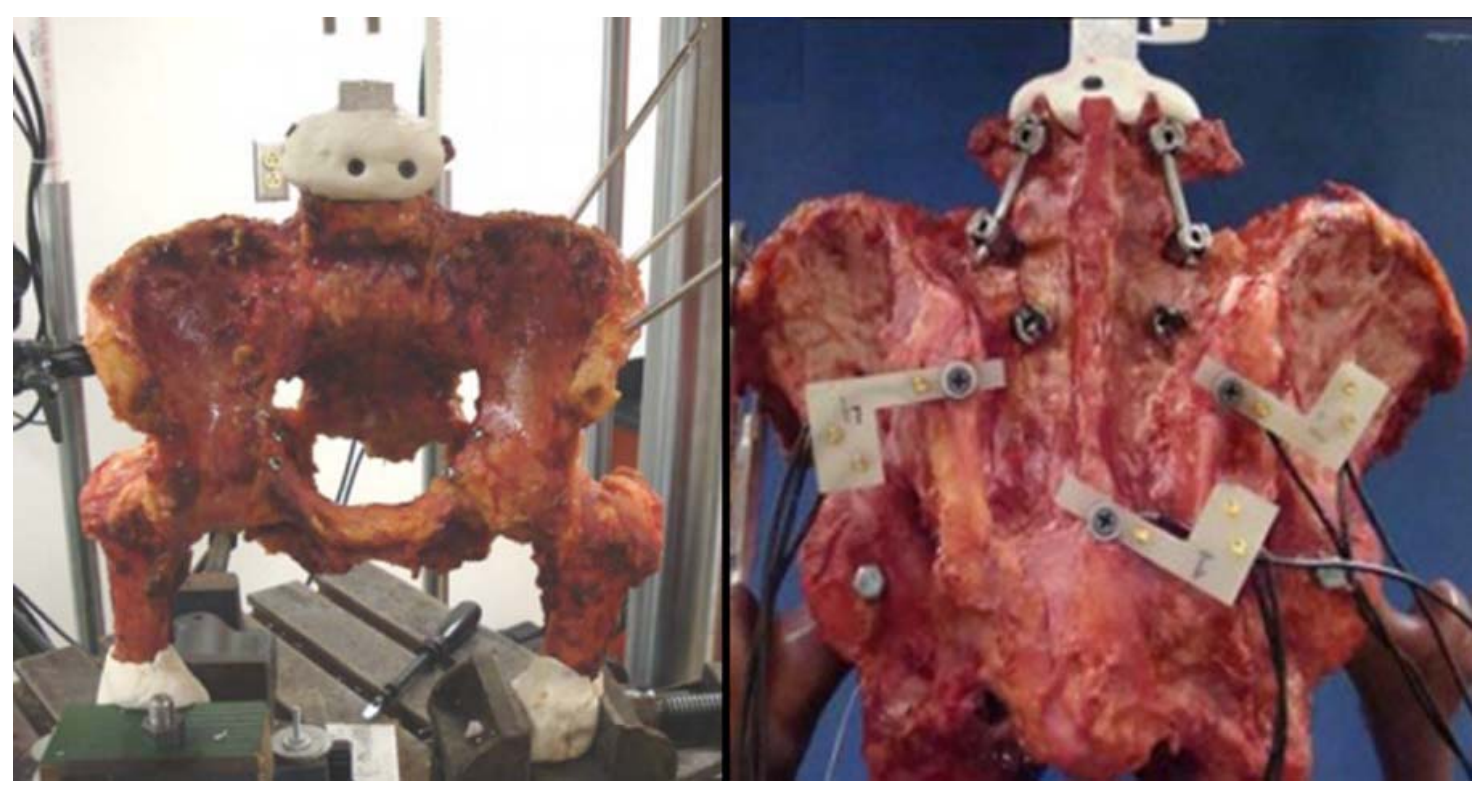

Figure 7. Biomechanical study on intact sacroiliac joint, double-leg stance model (left) and posterior view after L4-L5 fusion (right). ${ }^{44}$

In conclusion, in vitro studies have shown the efficacy of various implants in reducing the motion across the SIJ. Several questions, such as the mechanism for implant/bone failure, load distribution at bone-implant interface, the location of the critical load, and stresses and strains in the connective tissue and ligaments across the joint remain unanswered. Such limitations necessitate in silico modeling to quantify and compare data, using experimentally validated computational models.

\section{In Silico Studies}

Several authors have investigated the biomechanics of the SIJ after spinal or SIJ fusion using a computational approach. ${ }^{45-47}$

Mao et $\mathrm{al}^{48}$ investigated the effect of lumbar lordosis alteration on sacrum angular displacement after lumbosacral fusion using finite element analysis. Decreasing and increasing lumbar lordosis resulted in increased sacrum angular motion. In addition, fusion at the L4-S1 level resulted in higher sacrum angular displacement compared with L3L5-level fusion simulation. This supports the clinical observations that SIJ degeneration incidence is higher in fusions up to S1 rather than L5.

Ivanov et $\mathrm{al}^{49}$ evaluated sacrum angular motion and stresses across SIJ after lumbar fusion across L4-L5, L5-S1, and L4-S1 (Figure 8). Fusion resulted in an increase of SIJ motion and stresses across the SIJ. L4-S1-level fusion led to the highest increases, compared with fusions at other levels.
Bruna-Rosso et $\mathrm{al}^{50}$ analyzed SIJ biomechanics for RI-ALTO fusion implants (Figure 9). A compression load $(1000 \mathrm{~N})$ to the finite element model to simulate the experimental part of the study. They evaluated the effects of simulating 1 and 2 implants and their placement location across the SIJ. Proximal insertion of the implant placed farther from the SIJ center of rotation was more efficient than its distal insertion location. Proximal insertion of 1 implant even had better performance than using 2 implants in terms of motion reduction. There was not much difference in providing stability between 2 placement trajectories: medial and oblique for 1implant instrumentation. However, medial placement provided higher stability compared with oblique in 2-implant instrumentation simulation. Overall, the more parallel and farther from the SIJ center of rotation implant placement was, the higher the stability.

Zhang et $\mathrm{al}^{51}$ studied the biomechanical stability of SIJ screw fixation under 2 types of SIJ dislocations (Figure 10). For each dislocation model, they placed implants at the SIJ in 4 different configurations: a single screw in $\mathrm{S} 1$, single screw in $\mathrm{S} 2,2$ screws in $\mathrm{S} 1$, and 1 screw in $\mathrm{S} 1$ and another single screw in $\mathrm{S} 2$. Inferior translation, flexion, and lateral bending data were calculated. In one model, both long and short posterior sacroiliac ligaments were absent and no ligaments were present in the second model. The weakest placement configuration was the single screw in S2 in both injury types due to placement farther from the $\mathrm{S} 1$ endplate. Two screws at $\mathrm{S} 1$ and $\mathrm{S} 2$ were 


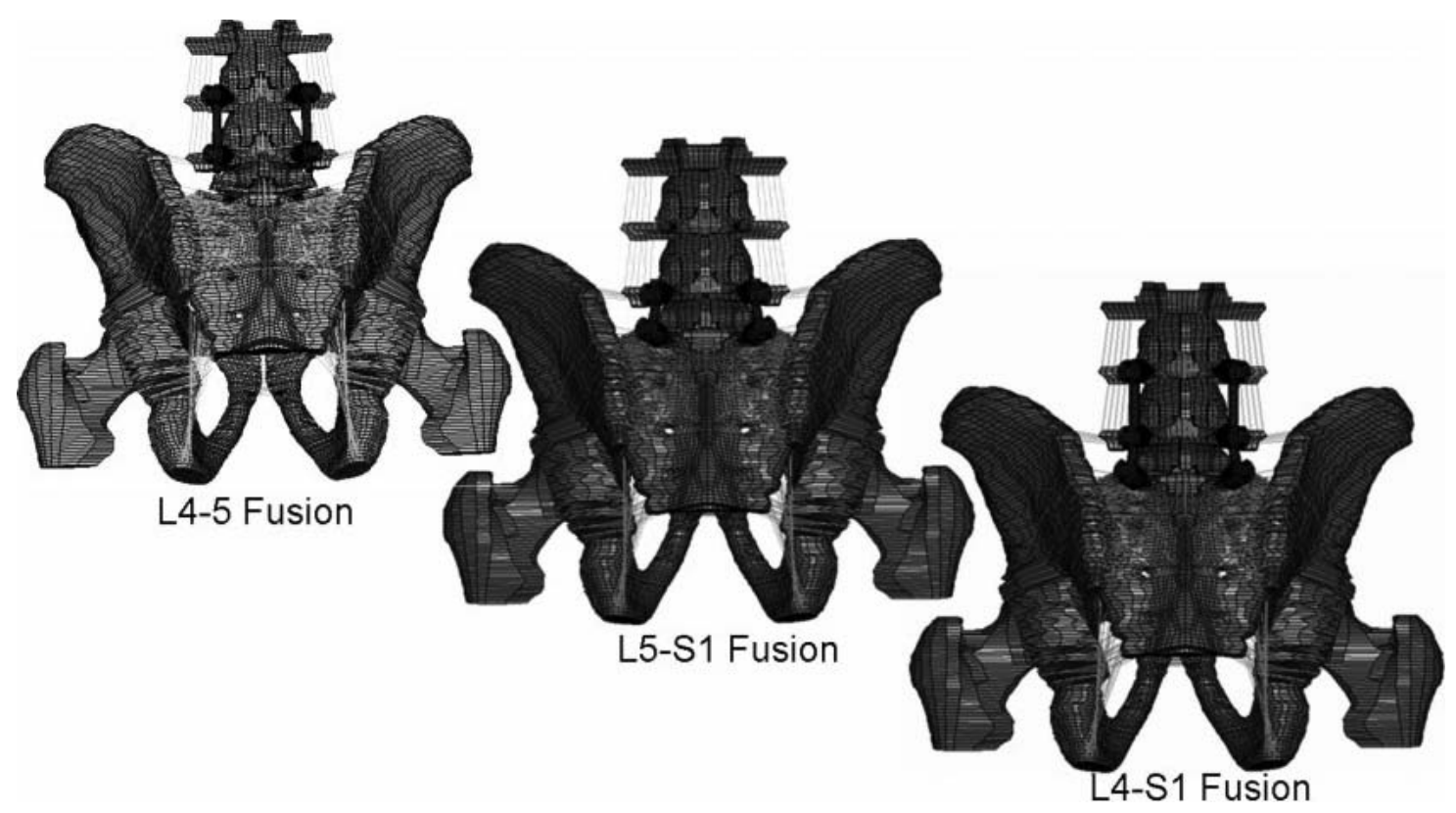

Figure 8. Finite element model with spinal fusions in different levels. ${ }^{49}$

the strongest placement, compared with placing 2 screws closely in $\mathrm{S} 1$ in both dislocation types.

Joukar et $a l^{52}$ investigated the effect of unilateral and bilateral SIJ fusion and different placements of fully threaded and half-threaded screws during standing upright (similar to the RI-ALTO and SILOK implant systems), on the SIJ male and female models' ROM and stresses (Figure 11). The fully threaded and half-threaded screws were located posterior and lateral into the SIJ, respectively. Unilateral stabilization significantly reduced the fused SIJ ROM along with reduction in contralateral (nonfused) SIJ motion during standing upright. Moreover, regardless of sex, lateral and posterior placements of the implants had similar performance on the SIJ stability. Both male and female models showed high reduction in stress and ROM after treatment compared with the intact model; however, female model showed more stress and motion reductions after SIJ fusion due to higher stress and ROM values in prior fusion compared to the male model. SIJ implants are more effective in females in terms of stability but may be more prone to higher rate of loosening or failure compared with males. The motion reduction at the SIJ after unilateral and bilateral fusions resulted in minimal changes at the adjacent lumbar levels for both male and female models. Although the implant shape effects were minimal, the implant placements played a major role in stresses on the bone and implant. In both unilateral and bilateral fusions, SIJ stabilization was primarily due to the inferior and superior implants.

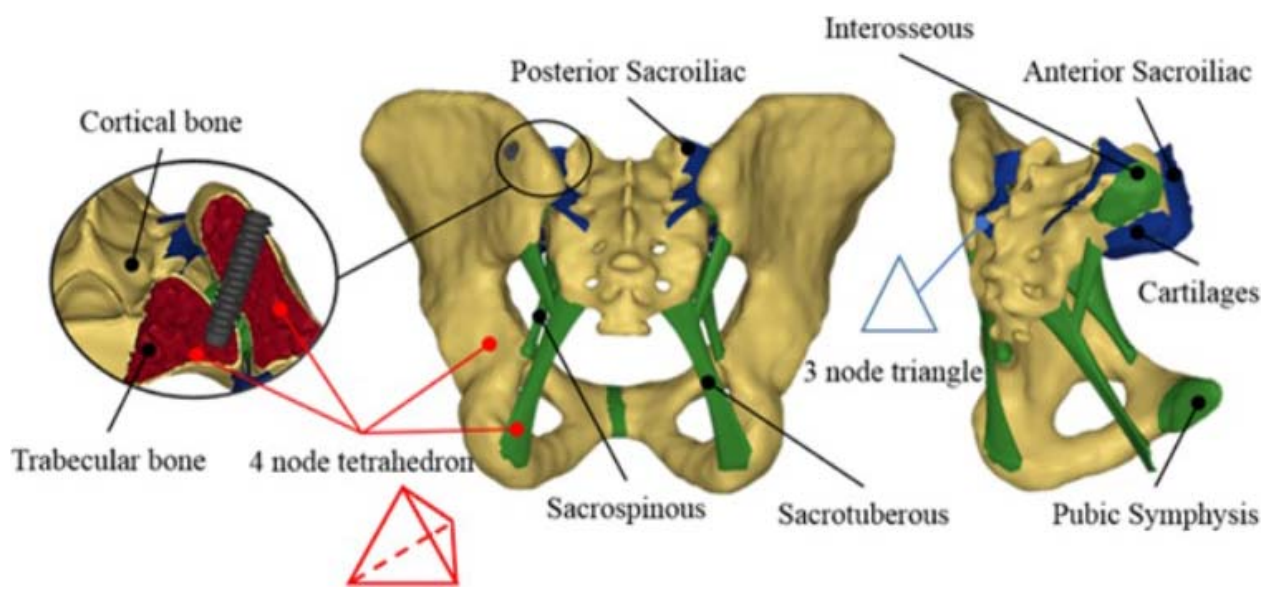

Figure 9. Finite element model of pelvis instrumented with RIALTO implant. ${ }^{50}$ 


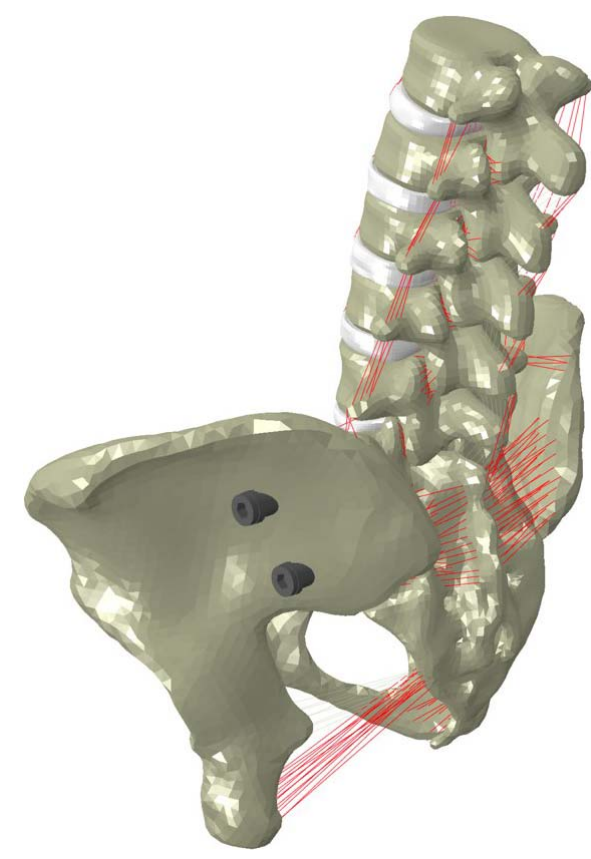

Figure 10. Finite element model of pelvis instrumented with one screw in S1 and another one in S2. ${ }^{51}$

Lindsey et $\mathrm{al}^{53}$ performed another finite element study on SIJ fusion with triangular implants to assess the biomechanical effects of length, orientation, and number of implants under all 6 spine motions (Figure 12). The following variables were simulated: 1, 2, and 3 implants, superior implant length of $55 \mathrm{~mm}$ or $75 \mathrm{~mm}$, midline implant length of $45 \mathrm{~mm}$, and inferior implant length of $45 \mathrm{~mm}$ for inline orientation and $50 \mathrm{~mm}$ for transarticular orientation. Transarticular orientation provided better fixation compared with inline orientation due to crossing more of the cartilaginous portion of the SIJ, although Soriano-Baron ${ }^{39}$ revealed that there was no significant difference between these 2 approaches. Use of a longer superior implant led to higher reduction in SIJ motion under different spine motions. In addition, placing 2 implants closer together yielded less stability than 2 implants far from each other. Overall, placing implants in the thicker cortical bone areas and a more dense bone region provided more stability.

In another finite element study by Lindsey et al, ${ }^{54}$ biomechanics of SIJ following various positioning configurations of triangular implants was evaluated. Simulations included altering implant orientation, superior implant length, and number of implants. They predicted that putting 3 implants across the SIJ using a transarticular orientation with the superior implant closer to the sacral midline led to the most stable construct.
As has been shown earlier, the lumbar segment fusion affects SIJ biomechanics. Lindsey et $\mathrm{al}^{53}$ assessed the ROM of the SIJ and the adjacent lumbar spinal motion segments after SIJ fusion using triangular implants. They showed that SIJ fusion using 3 triangular implants provided a significant reduction in SIJ motion in all 6 motions and resulted in an insignificant increase in adjacent lumbar segment motion.

Joukar et $\mathrm{al}^{55}$ developed a validated finite element model of the lumbo-pelvic segment to investigate the biomechanical effects of fixation of sacroiliac joint using triangular implants on the hip joint (Figure 13). Their model included the most critical anatomical features including connective tissue and articular cartilage across the hip joint. They performed an analysis with femurs fixed in a double-leg stance configuration and application of a 400-N compressive follower pre-load applied across the lumbo-sacral segment followed by a 10 $\mathrm{Nm}$ bending moment applied to the topmost level of the spine segment. The intact model was modified to include SIJ fixation, and unilateral and bilateral joint instrumentations. The analyses demonstrated a decrease in ROM of the SIJ in the instrumented model, compared with the intact. The bilateral fixation resulted in a greater reduction in motion compared with unilateral fixation. The contact stresses and load sharing did not significantly change in contralateral SIJs following unilateral fixation.

The average hip-contact stress and contact area changed less than $5 \%$ and $10 \%$, respectively, in instrumented models relative to intact models in most of anatomical motions. The data suggested a low risk of developing adjacent segment disease across the hip joint due to minimal changes in contact area and load sharing at the hip joint following instrumentation with the triangular implant compared with the intact state. The changes in the lumbar spine segment were minimal as well.

\section{SUMMARY}

One of the most overlooked sources of LBP is the SIJ due to its complex nature and the fact that pain emanating from this region can mimic other hip and spine conditions. The first step in the treatment of SIJ dysfunction involves nonsurgical management. When nonsurgical management strategies fail, surgical management (open or minimal fusion) is considered. 
$\mathbf{a}$

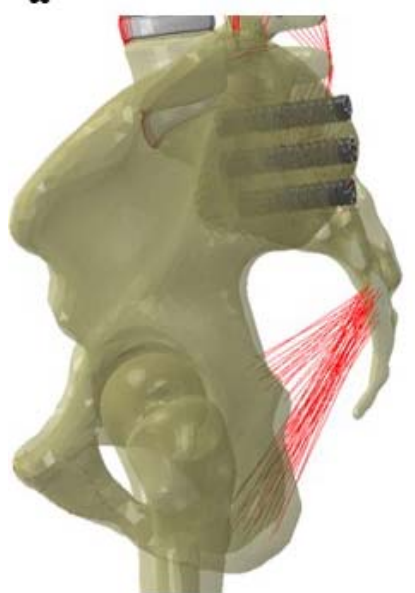

d

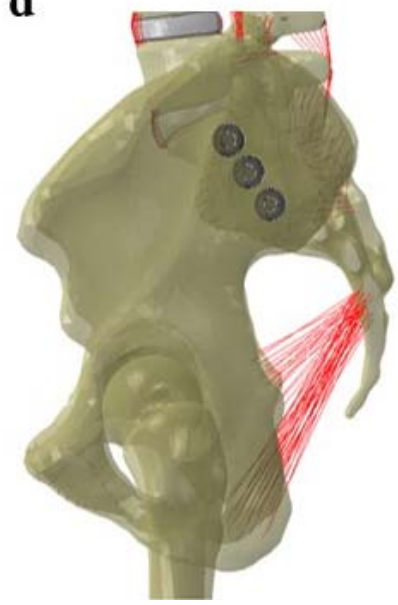

b

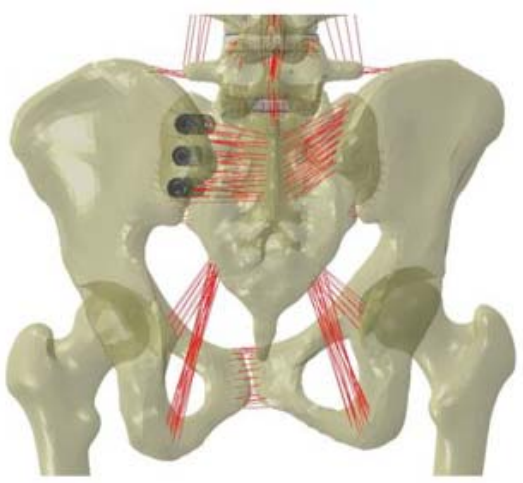

$\mathbf{e}$

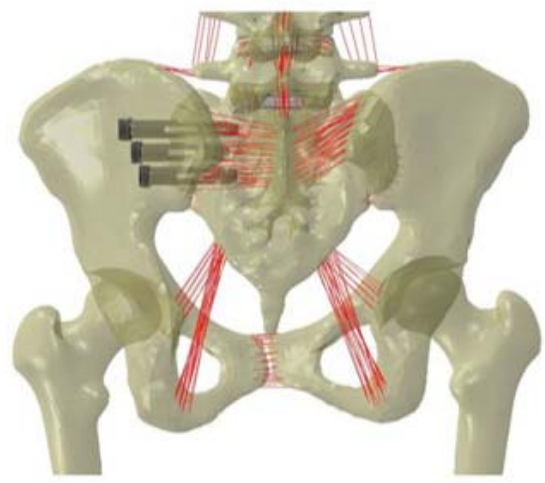

c

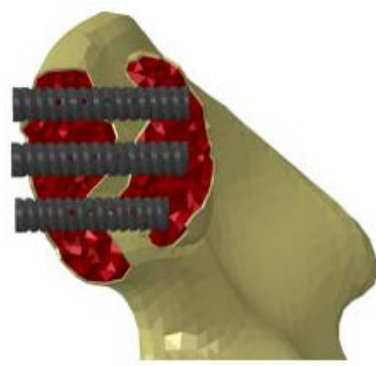

f

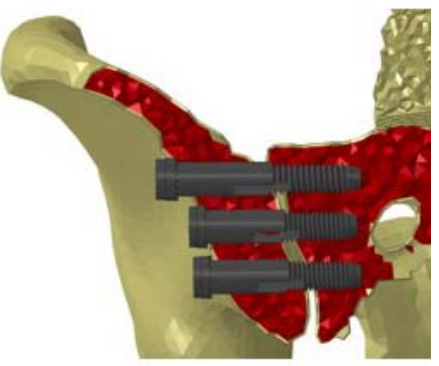

Figure 11. Lateral, posterior, and cross-section views of finite element model instrumented with fully threaded screws (a-c) and lateral, posterior, and cross-section views of finite element model instrumented with half-threaded screws $(d-f){ }^{52}$

Figure 12. Finite element spine-pelvis-femur model instrumented with iFuse triangular implants; posterior view (left) and side view (right)..$^{53}$

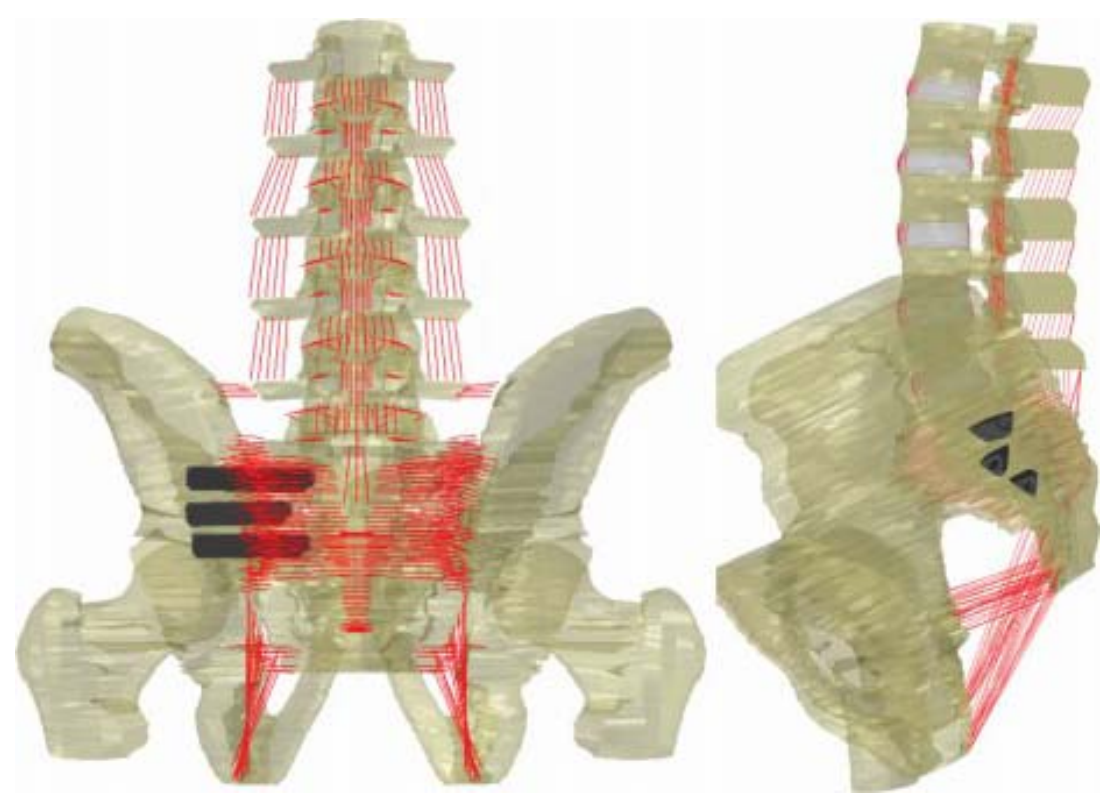




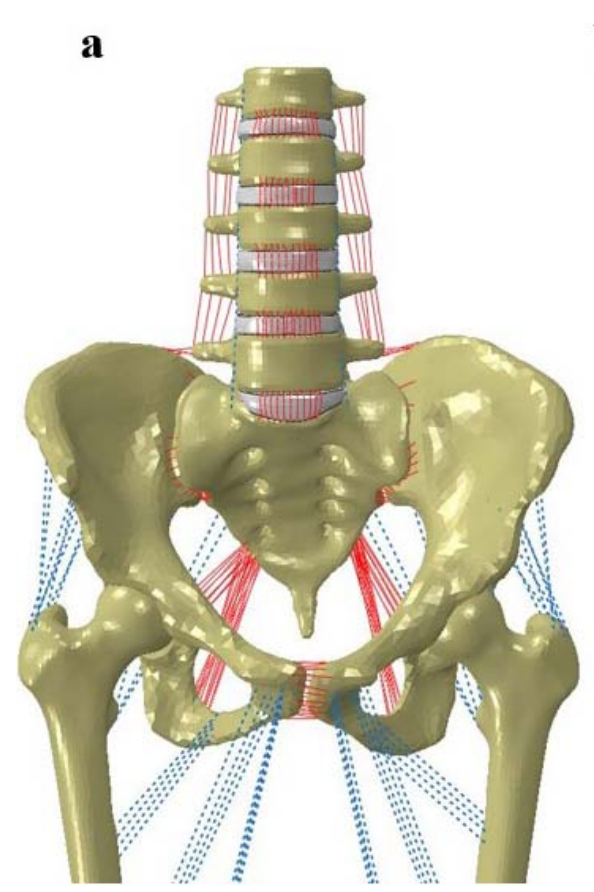

b

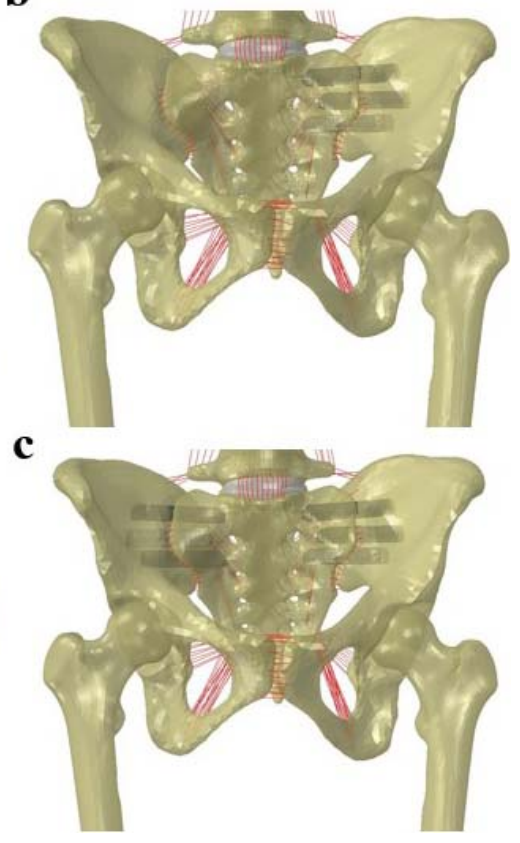

Figure 13. Finite element model of spinepelvis-femur: intact model including muscles (blue dashed lines), ligaments (red lines) (a); left unilaterally and bilaterally treated models using iFuse implant $(b, c) .{ }^{55}$
Several studies have investigated the clinical outcomes of surgical techniques for the SIJ. The studies have shown that minimally invasive techniques involve less tissue damage, blood loss, and duration of hospitalization, thus leading to superior clinical outcomes.

Despite the satisfactory data on clinical outcomes of SIJ fixation surgery, the data on biomechanics of the SIJ in general and fixation techniques in particular are sparse. The existing literature suggests that at least 2 fixation devices spaced apart in their locations on either side of the pivot point of SIJ facilitates "solid" fixation/stabilization across the joint. However, 1 more implant may further enhance the SIJ fixation. Both unilateral and bilateral SIJ fusions reduce motion. However, if bilateral SIJ fusion is considered, it is essential to ensure that implant design and SIJ morphology permit such a procedure.

Both males and females showed high performance after SIJ fusion treatment; however, females showed greater stress and motion reductions after SIJ fusion. Regardless of sex, lateral and posterior placements of the implants had similar performance on the SIJ stability. SIJ implants are more effective in females in terms of stability but may be more prone to higher rate of loosening or failure compared with males. The optimum number of implants and implant placement location are 2 or 3 implants (depending on the bone quality and implant type) across the S1 and S2 levels of the sacrum. Having implant placement more parallel and farther from the SIJ pivot point results in greater stability of the joint. Using a longer superior implant placed at the S1 level (proximally) closer to the sacral midline leads to greater reduction in SIJ motion. It is better to place the implant in thicker cortical bone areas and a more dense bone region, leading to better stability. Most importantly, SIJ fusion has no effect on the adjacent segments on either side: spine or hip.

Finally, regarding the shapes of the implants, currently there are 2 popular designs on the market: circular sections like SImmetry, SI-LOK, and RIALTO, and a triangular design like iFuse. Further biomechanical studies and long-term clinical followups are required to delineate the optimum design (eg, implant shape) since the existing literature on biomechanics of circular SIJ devices (SImmetry and SI-LOK implant systems) is limited.

In conclusion, despite the existing literature, there are several unanswered questions related to the effect of surgical parameters on the clinical outcome of the SIJ fixation procedures. For example, the effects of different implant shapes on the biomechanical and long-term clinical outcomes of the SIJ are not fully understood. It is particularly crucial to understand the relationship between bone quality or density and the effectiveness of the surgical technique from a biomechanical perspective, and the long-term clinical outcomes. Such questions can be answered by looking at parameters such as load- 
sharing at the bone-implant interface, distribution of the load across the implant, failure mechanism of the bone or implant, and bone remodeling. The clinical studies, due to their inherent limitations, are unable to address such issues. Such knowledge will be crucial for improvement of existing techniques or development of more efficient instrumentation that would yield superior clinical outcomes for SIJ fixation.

\section{REFERENCES}

1. Frymoyer JW. Back pain and sciatica. $N$ Engl $J$ Med. 1988;318(5):291-300.

2. Weksler N, Velan GJ, Semionov M, et al. The role of sacroiliac joint dysfunction in the genesis of low back pain: the obvious is not always right. Arch Orthop Trauma Surg. 2007;127(10):885-888.

3. Murray W. Sacroiliac joint dysfunction: a case study. Orthop Nurs. 2011;30(2):126-131; quiz 132-133.

4. Rudolf L. Sacroiliac joint arthrodesis-MIS technique with titanium implants: report of the first 50 patients and outcomes. Open Orthop J. 2012;6:495-502.

5. Saavoss JD, Koenig L, Cher DJ. Productivity benefits of minimally invasive surgery in patients with chronic sacroiliac joint dysfunction. Clinicoecon Outcomes Res. 2016;8:77-85.

6. Lingutla KK, Pollock R, Ahuja S. Sacroiliac joint fusion for low back pain: a systematic review and meta-analysis. Eur Spine J. 2016;25(6):1924-1931.

7. Sachs D, Capobianco R. One year successful outcomes for novel sacroiliac joint arthrodesis system. Ann Surg Innov Res. 2012;6(1):13.

8. Schwarzer AC, Aprill CN, Bogduk N. The sacroiliac joint in chronic low back pain. Spine (Phila Pa 1976). 1995;20(1):3137.

9. DonTigny RL. Function and pathomechanics of the sacroiliac joint. A review. Phys Ther. 1985;65(1):35-44.

10. Cohen SP. Sacroiliac joint pain: a comprehensive review of anatomy, diagnosis, and treatment. Anesth Analg. 2005;101(5):1440-1453.

11. Laslett M, Aprill CN, McDonald B, Young SB. Diagnosis of sacroiliac joint pain: validity of individual provocation tests and composites of tests. Man Ther. 2005;10(3):207-218.

12. Laslett M. Pain provocation tests for diagnosis of sacroiliac joint pain. Aust J Physiother. 2006;52(3):229.

13. Battafarano DF, West SG, Rak KM, Fortenbery EJ, Chantelois AE. Comparison of bone scan, computed tomography, and magnetic resonance imaging in the diagnosis of active sacroiliitis. Semin Arthritis Rheum. 1993;23(3):161-176.

14. Docherty P, Mitchell MJ, MacMillan L, Mosher D, Barnes DC, Hanly JG. Magnetic resonance imaging in the detection of sacroiliitis. J Rheumatol. 1992;19(3):393-401.

15. Murphey MD, Wetzel LH, Bramble JM, Levine E, Simpson KM, Lindsley HB. Sacroiliitis: MR imaging findings. Radiology. 1991;180(1):239-244.

16. Foley BS, Buschbacher RM. Sacroiliac joint pain: anatomy, biomechanics, diagnosis, and treatment. Am J Phys Med Rehabil. 2006;85(12):997-1006.
17. Kiapour A, Abdelgawad AA, Goel VK, Souccar A, Terai T, Ebraheim NA. Relationship between limb length discrepancy and load distribution across the sacroiliac joint - a finite element study. J Orthop Res. 2012;30(10):1577-1580.

18. Smith AG, Capobianco R, Cher D, et al. Open versus minimally invasive sacroiliac joint fusion: a multi-center comparison of perioperative measures and clinical outcomes. Ann Surg Innov Res. 2013;7(1):14.

19. Gatchel RJ, Mayer TG, Eddington A. MMPI disability profile: the least known, most useful screen for psychopathology in chronic occupational spinal disorders. Spine (Phila Pa 1976). 2006;31(25):2973-2978.

20. Duhon BS, Cher DJ, Wine KD, Lockstadt H, Kovalsky D, Soo CL. Safety and 6-month effectiveness of minimally invasive sacroiliac joint fusion: a prospective study. Med Devices (Auckl). 2013;6:219-229.

21. Sachs D, Capobianco R. Minimally invasive sacroiliac joint fusion: one-year outcomes in 40 patients. Adv Orthop. 2013;2013:536128.

22. Lindsey DP, Perez-Orribo L, Rodriguez-Martinez N, et al. Evaluation of a minimally invasive procedure for sacroiliac joint fusion - an in vitro biomechanical analysis of initial and cycled properties. Med Devices (Auckl). 2014;7:131-137.

23. Wang MY, Lu Y, Anderson DG, Mummanen PV. Minimally Invaisive Sacroiliac Joint Fusion. In: Anderson DG, Lu Y, Mummaneni PV, Wang M, eds. Minimally invasive spinal deformity surgery. VVienna: Springer; 2014:321-330.

24. Wang M, Dumas GA. Mechanical behavior of the female sacroiliac joint and influence of the anterior and posterior sacroiliac ligaments under sagittal loads. Clin Biomech (Bristol, Avon). 1998;13(4-5):293-299.

25. Lindsey DP, Parrish R, Gundanna M, Leasure J, Yerby SA, Kondrashov D. Biomechanics of unilateral and bilateral sacroiliac joint stabilization: laboratory investigation. $J$ Neurosurg Spine. 2018;28(3):326-332.

26. Rappoport LH, Luna IY, Joshua G. Minimally invasive sacroiliac joint fusion using a novel hydroxyapatite-coated screw: preliminary 1-year clinical and radiographic results of a 2-year prospective study. World Neurosurg. 2017;101:493-497.

27. Beaubien B, Salib R, Fielding L, Block JE. SImmetry sacroiliac joint fusion system with SImmetry decorticator. Surg Sci. 2015;6(7)282-291.

28. Mason LW, Chopra I, Mohanty K. The percutaneous stabilisation of the sacroiliac joint with hollow modular anchorage screws: a prospective outcome study. Eur Spine J. 2013;22(10):2325-2331.

29. Beck CE, Jacobson S, Thomasson E. A retrospective outcomes study of 20 sacroiliac joint fusion patients. Cureus. 2015;7(4):e260.

30. Hoel RJ, Ledonio CG, Takahashi T, Polly DW Jr. Sacral bone mineral density (BMD) assessment using opportunistic CT scans. J Orthop Res. 2017;35(1):160-166.

31. Harimaya K, Mishiro T, Lenke LG, Bridwell KH, Koester LA, Sides BA. Etiology and revision surgical strategies in failed lumbosacral fixation of adult spinal deformity constructs. Spine (Phila Pa 1976). 2011;36(20):1701-1710.

32. Lu WW, Zhu Q, Holmes AD, Luk KD, Zhong S, Leong JC. Loosening of sacral screw fixation under in vitro fatigue loading. J Orthop Res. 2000;18(5):808-814.

33. Matta JM, Saucedo T. Internal fixation of pelvic ring fractures. Clin Orthop Relat Res. 1989;242:83-97. 
34. Chip Routt ML Jr, Simonian PT. Closed reduction and percutaneous skeletal fixation of sacral fractures. Clin Orthop Relat Res. 1996;329:121-128.

35. Conflitti JM, Graves ML, and Chip Routt ML Jr. Radiographic quantification and analysis of dysmorphic upper sacral osseous anatomy and associated iliosacral screw insertions. J Orthop Trauma. 2010;24(10):630-636.

36. Carlson DA, Scheid DK, Maar DC, Baele JR, Kaehr DM. Safe placement of S1 and S2 iliosacral screws: the "vestibule" concept. J Orthop Trauma. 2000;14(4):264-269.

37. Gautier E, Bachler R, Heini PF, Nolte LP. Accuracy of computer-guided screw fixation of the sacroiliac joint. Clin Orthop Relat Res. 2001;393:310-317.

38. Gardner MJ, Morshed S, Nork SE, Ricci WM, Chip Routt ML Jr. Quantification of the upper and second sacral segment safe zones in normal and dysmorphic sacra. J Orthop Trauma. 2010;24(10):622-629.

39. Soriano-Baron H, Lindsey DP, Rodriguez-Martinez N, Reyes PM, Newcomb A, Yerby SA, Crawford NR. The effect of implant placement on sacroiliac joint range of motion: posterior versus transarticular. Spine (Phila Pa 1976). 2015;40(9):E525-30.

40. Jeong JH, Leasure JM, Park J. Assessment of Biomechanical Changes After Sacroiliac Joint Fusion by Application of the 3-Dimensional Motion Analysis Technique. World Neurosurg. 2018;117:e538-e543.

41. Shih YC, Beaubien BP, Chen Q, Sembrano JN. Biomechanical evaluation of sacroiliac joint fixation with decortication. Spine J. 2018;18(7):1241-1249.

42. Doud DM. Biomechanical Evaluation of a Novel Sacroiliac Fusion Technique [dissertation]. Birmingham, AL: The University of Alabama at Birmingham; 2017.

43. Cross WW, Berven SH, Slater N, Lehrman JN. In vitro biomechanical evaluation of a novel, minimally invasive, sacroiliac joint fixation device. Int J Spine Surg. 2018 Oct 15;12(5):587-594.

44. Bariah D. Sacroiliac Joint Biomechanics and Effects of Fusion [dissertation]. Miami, FL: University of Miami; 2010.

45. Joukar A, Mehta J, Marks D, Goel VK. Lumbar-sacral destruction fixation biomechanics: a finite element study. Spine J. 2017;17(11):S335.

46. Joukar A, Shah A, Kiapour A, et al. Goel, Sex specific sacroiliac joint biomechanics during standing upright: a finite element study. Spine (Phila Pa 1976). 2018;43(18):E1053E1060.

47. Seyed Vosoughi A, Joukar A, Kiapour A, et al. Optimal satellite rod constructs to mitigate rod failure following pedicle subtraction osteotomy (PSO): a finite element study. Spine J. 2019;19(5):931-941.

48. Mao N, Shi J, He D, et al. Effect of lordosis angle change after lumbar/lumbosacral fusion on sacrum angular displace- ment: a finite element study. Eur Spine J. 2014;23(11):23692374.

49. Ivanov AA, Kiapour A, Ebraheim NA, Goel V. Lumbar fusion leads to increases in angular motion and stress across sacroiliac joint: a finite element study. Spine (Phila Pa 1976). 2009;34(5):E162-169.

50. Bruna-Rosso C, Arnoux PJ, Bianco RJ, Godio-Raboutet Y, Fradet L, Aubin CE. Finite element analysis of sacroiliac joint fixation under compression loads. Int $J$ Spine Surg. 2016;10:16

51. Zhang L, Peng Y, Du C, Tang P. Biomechanical study of four kinds of percutaneous screw fixation in two types of unilateral sacroiliac joint dislocation: a finite element analysis. Injury. 2014;45(12):2055-2059.

52. Joukar A. Gender Specific Sacroiliac Joint Biomechanics: A Finite Element Study [thesis]. Toledo, $\mathrm{OH}$ : The University of Toledo; 2017.

53. Lindsey DP, Kiapour A, Yerby SA, Goel VK. Sacroiliac joint fusion minimally affects adjacent lumbar segment motion: a finite element study. Int J Spine Surg. 2015 Nov 13;9:64.

54. Lindsey DP, Kiapour A, Yerby SA, Goel VK. Sacroiliac joint stability: finite element analysis of implant number, orientation, and superior implant length. World J Orthop. 2018;9(3):14-23.

55. Joukar A, Chande RD, Carpenter RD, et al. Effects on hip stress following sacroiliac joint fixation: a finite element study. JOR Spine. 2019;2(4)e1067.

Disclosures and COI: Work was supported in part by the National Science Foundation Industry/ University Cooperative Research Center, University of California at San Francisco and University of Toledo and research grants from SI-Bone, Inc., Santa Clara, California.

Corresponding Author: Vijay K. Goel, PhD, Departments of Bioengineering and Orthopaedic Surgery, Colleges of Engineering and Medicine, 5046 NI, MS 303, College of Engineering, University of Toledo, Toledo, OH 43606. Phone: (419) 5308035; Fax: (419) 530-8076; Email: Vijay.Goel@ utoledo.edu.

Published 30 June 2020

This manuscript is generously published free of charge by ISASS, the International Society for the Advancement of Spine Surgery. Copyright (C) 2020 ISASS. To see more or order reprints or permissions, see http://ijssurgery.com. 